\title{
Autonomic control of cardiovascular system in pre- and postmenopausal women: a cross-sectional study
}

\author{
Irina W. Neufeld ${ }^{1}$, Anton R. Kiselev ${ }^{2,3}$, Antoly S. Karavaev ${ }^{3}$, Mikhail D. Prokhorov ${ }^{4}$, Vladimir I. Gridnev ${ }^{2,3}$, \\ Vladimir I. Ponomarenko ${ }^{3}$, Boris P. Bezruchko ${ }^{3}$ \\ 'Department of Obstetrics and Gynecology, Saratov State Medical University, Saratov, Russia \\ ${ }^{2}$ Centre of New Cardiological Informational Technologies, Research Institute of Cardiology, Saratov State Medical \\ University n.a. V.I. Razumovsky, Saratov, Russia \\ ${ }^{3}$ Department of Nano- and Biomedical Technologies, Saratov State University, Saratov, Russia \\ ${ }^{4}$ Saratov Branch of the Institute of Radio Engineering and Electronics, Saratov, Russia
}

\section{Abstract}

Objective: The aim of this cross-sectional study was to assess the features of autonomic control of the cardiovascular system in pre- and postmenopausal women.

Material and Methods: We studied 185 postmenopausal women aged 59.3 \pm 8.5 years (mean \pm SD) and 104 premenopausal women aged $45.1 \pm 5.8$ years. Standard indices of heart rate variability (HRV) (mean heart rate, coefficient of variation, standard deviation of the NN interval (the time elapsing between two consecutive R waves in the electrocardiogram with normal sinus rhythm) (SDNN), square root of the mean squared differences of successive NN intervals (RMSSD), proportion derived by dividing RR50, the number of interval differences of successive NN intervals greater than $50 \mathrm{~ms}$, by the total number of NN intervals (PNN50), and power of low frequency (LF) and high frequency (HF) bands in absolute values and percentages of total spectral power) and index $\mathrm{S}$ of synchronization between the $0.1-\mathrm{Hz}$ rhythms in heart rate and photoplethysmogram were compared between these two groups at rest. We assessed the following sex hormones: estradiol, follicle stimulating hormone, dehydroepiandrosterone sulfate, and testosterone.

Results: Mean heart rate and power of LF and HF bands were significantly different $(\mathrm{p}<0.05)$ in pre- and postmenopausal women. The autonomic indices were similar in women with natural and surgical menopause. Some indices (coefficient of variation, SDNN, RMSSD, PNN50, and power of LF and HF bands) showed weak correlation with menopause time in women with natural menopause. In women with surgical menopause, a moderate statistically significant correlation was observed only between menopause time and $\mathrm{S}$ index ( $\mathrm{r}=-0.41, \mathrm{p}=0.039$ ). In premenopausal women, only testosterone correlated weakly with coefficient of variation, SDNN, PNN50, RMSSD, and power of HF band. In postmenopausal women, no correlations were found. We did not find any significant relationship between autonomic indices and hot flashes, assessed by hot flash diary.

Conclusion: We did not find a clinically important relationship between cardiovascular autonomic control and menopausal status in women. (J Turk Ger Gynecol Assoc 2015; 16: 11-20)

Keywords: Autonomic control, menopause, heart rate variability, 0.1-Hz rhythms, sex hormones, hot flashes

Received: 28 October, $2014 \quad$ Accepted: 08 November, 2014

\section{Introduction}

The effect of menopause on cardiovascular disease (CVD) in women has been studied by Kannel et al. (1). It has been found that autonomic dysfunction is an important factor for the evaluation of risk of cardiovascular events in CVD patients $(2,3)$. Age-related changes in autonomic control of the cardiovascular system (CVS) are also well known (2, 4-6). The difference of heart rate variability (HRV) indices in pre- and postmenopausal women has been reported $(7,8)$. Vongpatanasin W. has studied the increase of sympathetic tone and blood pressure in menopause (9). Lee et al. (10) have found a relationship between menopausal symptoms and changes in cardiovascular autonomic regulation in women. For example, hot flashes and sleep disorders are strongly associated with increased sympathetic tone (10). Moreover, a significant decrease in cardiac vagal control occurs during hot flashes (11). These signs of autonomic dysfunction may be important for cardiovascular risk assessment. The influence of sex hormones, in particular, hormone replacement therapy (HRT), on cardiovascular autonomic control is controversial $(8,12-17)$. Moreover, several authors reported the influence of body mass index (BMI) on autonomic control in women (18). 
Autonomic control in CVS can be assessed by HRV analysis. Various time domain and frequency domain indices are usually used for this purpose (2). The physiological explanation of these indices is known $(2,19,20)$. These indices can assess cardiac autonomic regulation but not peripheral blood flow. In our previous papers, we have proposed an original method for the assessment of cardiovascular autonomic control based on synchronization between the $0.1-\mathrm{Hz}$ rhythms in heart rate (HR) and photoplethysmogram (PPG) (21). The quality of $0.1-\mathrm{Hz}$ rhythms synchronization was found to be higher in healthy subjects than in patients with cardiovascular disease (22). From a physiological viewpoint, the synchronization of $0.1-\mathrm{Hz}$ rhythms is the result of adequate functional interaction of CVS parts (heart and peripheral vessels). The clinical importance of this diagnostic method is shown for patients with prior myocardial infarction, patients with acute coronary syndrome, and hypertensive patients $(3,23)$.

The physiological explanation of $0.1-\mathrm{Hz}$ rhythms in PPG is a debatable point. An opto-physiological model of a finger in conjunction with a near-infrared reflectance PPG device has been proposed (24). It was shown that both oscillations in the microcirculatory bed and blood filling of digital arteries make a substantial contribution to the PPG signal. Therefore, $0.1-\mathrm{Hz}$ oscillations in PPG may be associated directly with baroreceptor regulation of blood pressure (BP). At the same time, a number of authors assume that $0.1-\mathrm{Hz}$ oscillations in blood microcirculation are not associated with autonomic regulation (25-28). To avoid confusion, we do not interpret the origin of $0.1-\mathrm{Hz}$ oscillations in PPG in the present paper.

Thus, the features of cardiovascular autonomic control in women before and after menopause are not fully understood. Controversial results concerning this problem have been reported. The aim of the present study cross-sectional study is to assess the features of autonomic control of CVS in pre- and postmenopausal women.

\section{Material and Methods}

\section{Patients}

The study was approved by the ethics committee of the Saratov Research Institute of Cardiology in Saratov, Russia (no. 24, Sept. $12,2013)$ and informed consent was obtained from all participants.

Our cross-sectional study included 185 postmenopausal women aged 59.3 \pm 8.5 years (mean \pm SD) and 104 premenopausal women aged $45.1 \pm 5.8$ years. Both groups were investigated and treated, if necessary, in the clinic of Saratov State Medical University (Saratov, Russia). Clinical characteristics (cardiovascular, gynecological, etc.) were assessed in all women. We assessed the level of the following sex hormones: estradiol, follicle-stimulating hormone (FSH), dehydroepiandrosterone sulfate (DHEAS), and testosterone. Only patients aged between 35 and 70 years were enrolled in our study. Women with CVD were not on beta-blockers or calcium channel blockers during the 7 days before the start of the study.

Patients were not included in our study if they matched the following criteria: i) valvular defect of the heart

ii) rhythm other than sinus that would impede analysis of HRV

iii) endocrine pathology, excluding diabetes mellitus

iv) chronic gastrointestinal diseases (hepatitis, gastric ulcer, duodenum disease, and cholecystitis), chronic diseases of the kidneys, and other chronic diseases in the stage of exacerbation

\section{Signal recording}

To examine the autonomic control of the CVS, we carried out HRV analysis and estimated the degree of synchronization between the $0.1-\mathrm{Hz}$ rhythms in HR and PPG. PPG, measured on the middle finger of the subject's hand; electrocardiogram (ECG); and respiration were simultaneously recorded at rest. The signals were recorded within 10 minutes in the supine position.

All subjects were investigated after afternoon fasting under spontaneous breathing. The signals were measured in a quiet, temperature-controlled room. All signals were sampled at 250 $\mathrm{Hz}$ and digitized at 14 bits. The record of respiration was used to control the evenness of breathing. We excluded series with forced inspiration and delays in breathing from the analysis. For further analysis, only ECG and PPG records without artifacts, extrasystoles, and considerable trends were left.

\section{Signal processing}

We analyzed HRV in the frequency domain and time domain using HR and PPG signals simultaneously recorded within 10 minutes. We evaluated the following time domain HRV parameters: mean heart rate (mean HR), standard deviation of the NN interval (the time elapsing between two consecutive $R$ waves in the electrocardiogram with normal sinus rhythm) (SDNN), coefficient of variation (CV), square root of the mean squared differences of successive NN intervals (RMSSD), and proportion derived by dividing NN50-the number of interval differences of successive NN intervals greater than 50 ms-by the total number of NN intervals (PNN50) (2).

High-frequency (HF) range, $0.15-0.4 \mathrm{~Hz}$, and low-frequency (LF) range, 0.04-0.15 Hz, of HRV were analyzed (2). Power of $\mathrm{LF}$ and HF bands in the HRV power spectrum was presented in absolute values $\left(\mathrm{ms}^{2}\right)$ and in percentage of total spectral power (LF\% and HF\%). LF /HF ratio was also calculated (2). Very-lowfrequency range of HRV was not included in our analysis to avoid questionable results, because we registered short-time ECG records (2).

To estimate synchronization between the $0.1-\mathrm{Hz}$ rhythms in HR and PPG, we used the method proposed by us recently (21). Index $S$ defines the relative time of synchronization between the $0.1-\mathrm{Hz}$ rhythms considered.

\section{Statistical analysis}

Continuous variables are reported as medians with interquartile ranges, Me (Q1, Q3). Categorical data are presented as frequencies and percentages. The obtained estimations were considered statistically significant if $p<0.05$. For the statistical analysis, the software package Statistica 6.1 (StatSoft Inc., Tulsa, Oklahoma, USA) was used. 
We applied the Shapiro-Wilk test to check whether the data were approximately normally distributed. Since these data were non-normal, their further analysis was carried out using non-parametric statistical methods. To compare the variables between patient groups, we used the Mann-Whitney test. To compare the variables within one patient group, we used the Wilcoxon test. Paired relationships between continuous variables were assessed using Spearman correlation coefficients (0.68-1.0 is high correlation, $0.36-0.67$ is moderate correlation, and $\leq 0.35$ is low correlation (29). For categorical variables, chi-square $\left(\chi^{2}\right)$ test was used to estimate their relationships. Multiple regression analysis with sigma-restricted parameterization was used to study multivariate effects for continuous and categorical variables.

Discriminant analysis was used to determine the set of studied parameters (clinical status, sex hormones, and cardiovascular autonomic indices) that resulted in the best separation of groups of women with hot flashes and without them.

Receiver operating characteristics (ROC) curves and corresponding area under curve (AUC) values were assessed for the binary classifier system with continuous predictors. AUC is presented with its 95\% confidence interval (CI). We also assessed sensitivity (Se) and specificity (Sp) and presented them with their $95 \%$ confidence interval.

\section{Results}

\section{Menopause, clinical status, and sex hormones}

The clinical characteristics of the pre- and postmenopausal women are presented in Table 1. Postmenopausal women had a greater frequency of hot flashes assessed by hot flash diary, angina pectoris, arterial hypertension, and diabetes mellitus than premenopausal women. We revealed a strong relationship between the level of sex hormones (estradiol, testosterone, FSH, and DHEAS) and menopause (AUC tends to 1.0).

In the postmenopausal group, natural and surgical menopause occurred in 161 and 26 women, respectively. The clinical characteristics of these subgroups are presented in Table 2. Women with surgical menopause were younger than other postmenopausal women and had a greater frequency of hot flashes, greater levels of FSH and DHEAS, and lower levels of estradiol and testosterone. Also, 4.4\% and 7.7\% of women with natural and surgical menopause, respectively, received hormone replacement therapy. Exclusion of these patients from consideration did not change the observed differences in sex hormone levels between the subgroups studied. Menopause time was similar in women with natural and surgical menopause (Table 2).

We constructed a discriminant model based on sex hormones, age, HRT (binary), CVD (binary), and BMI for prediction of hot flashes separately in pre- and postmenopausal women. In premenopausal women, the constructed discriminant model had Wilks' lambda $=0.72$ and approximate $\mathrm{F}(8.98)=4.74$ $(p<0.001)$. The percent of correctly classified cases using the constructed model was $50.0 \%$ for women with hot flashes and $88.8 \%$ for women without hot flashes. Summary statistics for all variables of the model are presented in Table 3 . The construct- ed model showed low discriminatory power (Wilks' lambda $>0.5$ for each variable and for the model on the whole). The main predictor of hot flashes was FSH.

In postmenopausal women, the constructed discriminant model had Wilks' lambda $=0.55$ and approximate $F(8.17)=17.81$ $(p<0.001)$. The percent of correctly classified cases using the constructed model was $82.8 \%$ for women with hot flashes and $82.1 \%$ for women without hot flashes, respectively. Summary statistics for all variables of the model are presented in Table 3. The main predictors of hot flashes were estradiol and age. We did not find any relationship between smoking and sex hormones $(p>0.1)$.

\section{Correlations across cardiovascular autonomic indices}

Many autonomic indices in our study correlated between themselves. Time domain indices (SDNN, CV, RMSSD, and PNN50) correlated strongly between themselves and with some frequency domain indices, but they did not correlate with HR, LF\%, and $S$ index. For example, SDNN had a Spearman correlation coefficient $\mathrm{r}>0.8, \mathrm{p}<0.001$ with all autonomic indices, excluding HR ( $\mathrm{r}=-0.29, \mathrm{p}<0.001), \mathrm{LF} \%(\mathrm{r}=0.02, \mathrm{p}=0.767)$, and $S$ index $(\mathrm{r}=-0.22, \mathrm{p}=0.003)$.

HR, LF\%, and $S$ index were the most independent autonomic indices in our study. We did not find any correlation between them $(r<0.1, p>0.05$ for all pairs). This observation was confirmed by multiple regression analysis, where adjusted $R^{2}$ took values from 0.12 to 0.15 in models for $\mathrm{HR}, \mathrm{LF} \%$, and $S$ index.

\section{Menopause and cardiovascular autonomic indices}

Most frequency domain and time domain parameters of cardiovascular autonomic control, excluding mean $\mathrm{HR}$, were similar in pre- and postmenopausal women (Table 1). Mean HR was greater in premenopausal women. For classification of pre- and postmenopausal women, the optimal point of HR was 70 beats/ min: $\mathrm{Se}=72.1 \%(95 \% \mathrm{CI}=62.5-80.5), \mathrm{Sp}=45 \% \quad(95 \% \mathrm{CI}=38.1-$ 52.9), and $\mathrm{AUC}=0.589$ (95\% $\mathrm{CI}=0.530-0.646)$.

After the exclusion of patients with CVD (coronary heart disease, myocardial infarction, hypertension, stroke, and diabetes mellitus) from the analysis, the difference between pre- and postmenopausal women was additionally identified using the absolute values of LF and HF bands of the HRV spectrum and RMSSD (Table 1). Healthy premenopausal women had lower values of LF and HF than premenopausal women with CVD. On the contrary, healthy postmenopausal women were characterized by greater values of these indices than CVD patients. We did not reveal a significant difference in autonomic parameters in women with natural and surgical menopause (Table 2).

We also studied the correlation between cardiovascular autonomic indices and menopause time in women with natural and surgical menopause, including CVD patients (Table 4). It was shown that time domain indices (SDNN, CV, RMSSD, and PNN50) and some frequency indices (HF, HF\%, and LF) correlated with menopause time in women with natural menopause $(p<0.05)$. But, the values of these correlations were low. In women with surgical menopause, a moderate statistically significant correlation was observed only between menopause 
Table 1. Clinical characteristics and cardiovascular autonomic indices in pre- and postmenopausal women

\begin{tabular}{|c|c|c|c|}
\hline \multirow[b]{2}{*}{ Parameters } & $\begin{array}{l}\text { Premenopausal } \\
\quad(n=104)\end{array}$ & $\begin{array}{l}\text { Postmenopausal } \\
\quad(n=187)\end{array}$ & \multirow[b]{2}{*}{$\mathbf{p}$} \\
\hline & $*(n=71)$ & $*(n=55)$ & \\
\hline Age, years & $46(41,49)$ & $60(53,65)$ & $<0.001$ \\
\hline Hot flashes & $13.6 \%$ & $57.8 \%$ & $<0.001$ \\
\hline Estradiol, pmol/L & $133(121,146)$ & $74(68,84)$ & $<0.001$ \\
\hline $\mathrm{FSH}, \mathrm{IU} / \mathrm{L}$ & $27(24,37)$ & $80(73,85)$ & $<0.001$ \\
\hline Testosterone, nmol/L & $1.7(1.3,2.0)$ & $1.3(1.1,1.5)$ & $<0.001$ \\
\hline DHEAS, nmol/L & $2.0(1.2,2.1)$ & $5.7(4.8,5.9)$ & $<0.001$ \\
\hline HRT & $1.9 \%$ & $4.9 \%$ & 0.208 \\
\hline Height, $\mathrm{m}$ & $1.64(1.60,1.67)$ & $1.63(1.59,1.65)$ & 0.096 \\
\hline Waist, kg & $73(64,86)$ & $72(66,84)$ & 0.452 \\
\hline $\mathrm{BMI}, \mathrm{kg} / \mathrm{m}^{2}$ & $26.5(24.2,31.4)$ & $27.1(25.1,31.6)$ & 0.155 \\
\hline SBP, mmHg & $120(110,135)$ & $135(120,140)$ & 0.021 \\
\hline DBP, mmHg & $80(70,100)$ & $90(80,100)$ & 0.035 \\
\hline CHD, angina pectoris & $6.7 \%$ & $29.9 \%$ & $<0.001$ \\
\hline Prior myocardial infarction & 0 & $2.7 \%$ & 0.089 \\
\hline Arterial hypertension & $26.9 \%$ & $55.4 \%$ & $<0.001$ \\
\hline Prior stroke & 0 & $2.2 \%$ & 0.131 \\
\hline Diabetes mellitus & 0 & $8.2 \%$ & 0.032 \\
\hline Smoking & $8.7 \%$ & $6.0 \%$ & 0.392 \\
\hline Mean HR, beats/min & $\begin{array}{c}75(69,82) \\
* 73(69,83) \\
\end{array}$ & $\begin{array}{c}72(65,80) \\
* 72(66,77) \\
\end{array}$ & $\begin{array}{c}0.012 \\
* 0.077\end{array}$ \\
\hline SDNN & $\begin{array}{c}32.8(24.0,48.9) \\
* 32.4(23.4,44.7) \\
\end{array}$ & $\begin{array}{l}33.7(24.9,53.9) \\
* 33.7(24.3,58.2) \\
\end{array}$ & $\begin{array}{c}0.371 \\
* 0.198 \\
\end{array}$ \\
\hline $\mathrm{CV}, \%$ & $\begin{array}{c}4.0(2.8,6.0) \\
* 3.9(2.8,5.5) \\
\end{array}$ & $\begin{array}{c}4.1(2.9,6.6) \\
* 4.1(2.9,7.3) \\
\end{array}$ & $\begin{array}{c}0.604 \\
* 0.282 \\
\end{array}$ \\
\hline RMSSD & $\begin{array}{c}23.1(13.3,42.9) \\
* 20.9(13.2,41.6)\end{array}$ & $\begin{array}{l}27.3(16.4,58.0) \\
* 26.1(17.1,57.9) \\
\end{array}$ & $\begin{array}{c}0.080 \\
* 0.048\end{array}$ \\
\hline PNN50 & $\begin{array}{c}1.5(0.2,6.2) \\
* 1.3(0.2,3.9)\end{array}$ & $\begin{array}{c}2.3(0.3,9.5) \\
* 1.9(0.2,11.2)\end{array}$ & $\begin{array}{l}0.159 \\
* 0.309\end{array}$ \\
\hline $\mathrm{HF}, \mathrm{ms}^{2}$ & $\begin{array}{l}75.2(29.7,204.2) \\
* 68.1(28.9,169.2)\end{array}$ & $\begin{array}{l}102.1(33.4,434.5) \\
* 88.2(50.4,665.4)\end{array}$ & $\begin{array}{l}0.055 \\
* 0.037\end{array}$ \\
\hline $\mathrm{LF}, \mathrm{ms}^{2}$ & $\begin{array}{l}106.9(54.8,225.7) \\
* 98.5(53.2,188.8)\end{array}$ & $\begin{array}{c}116.3(57.8,456.8) \\
* 143.4(65.3,456.8)\end{array}$ & $\begin{array}{c}0.277 \\
* 0.043\end{array}$ \\
\hline HF, \% & $\begin{array}{l}23.7(10.2,40.7) \\
* 21.0(10.1,41.5)\end{array}$ & $\begin{array}{l}26.8(14.6,41.0) \\
* 25.1(15.2,38.6)\end{array}$ & $\begin{array}{c}0.091 \\
* 0.301\end{array}$ \\
\hline LF, \% & $\begin{array}{c}27.9(20.9,35.1) \\
* 26.7(20.3,34.2)\end{array}$ & $\begin{array}{c}28.0(18.2,40.9) \\
* 28.1(19.9,41.6)\end{array}$ & $\begin{array}{c}0.793 \\
* 0.409\end{array}$ \\
\hline $\mathrm{S}, \%$ & $\begin{array}{c}46.9(40.3,55.9) \\
* 47.9(40.2,57.3)\end{array}$ & $\begin{array}{c}43.6(34.1,55.3) \\
* 42.3(31.3,55.0)\end{array}$ & $\begin{array}{c}0.087 \\
* 0.064\end{array}$ \\
\hline $\begin{array}{l}\text { Continuous variables are prese } \\
\text { follicle stimulating hormone; } D \\
\text { systolic blood pressure; DBP: } \\
\text { terval (the time elapsing betwe } \\
\text { RMSSD: square root of the me } \\
\text { interval differences of success } \\
\text { values }\left(\mathrm{ms}^{2}\right) \text {; LF: low frequenc } \\
\text { frequency band in percentage } \\
\text { *Data in patients without CVD }\end{array}$ & $\begin{array}{l}\text { drosterone sulfate; HR } \\
\text { re; CHD: coronary hea } \\
\text { R waves in the electroc } \\
\text { s of successive NN int } \\
\text { er than } 50 \mathrm{~ms} \text {, by the to } \\
\text { lues }\left(\mathrm{ms}^{2}\right) \text {; HF\%: high } \\
\text { er; S: Index S of synchr } \\
\text { history of stroke, diabe }\end{array}$ & $\begin{array}{l}\text { gorical data are presen } \\
\text { cement therapy; BMI: bc } \\
\text { art rate; SDNN: standarc } \\
\text { ormal sinus rhythm); C } \\
\text { pportion derived by divic } \\
\text { I intervals; HF: high freq } \\
\text { percentage of total spe } \\
\text { n the } 0.1-\text { Hz rhythms }\end{array}$ & $\begin{array}{l}\text { tages. FSH } \\
\text { ex; SBP: } \\
\text { the NN in- } \\
\text { of variation } \\
\text { e number o } \\
\text { h absolute } \\
\text { LF\%: low }\end{array}$ \\
\hline
\end{tabular}


Table 2. Clinical characteristics and cardiovascular autonomic indices in women with natural and surgical menopause

\begin{tabular}{|c|c|c|c|}
\hline Parameters & $\begin{array}{l}\text { Natural menopause } \\
\quad(\mathrm{n}=161)\end{array}$ & $\begin{array}{l}\text { Surgical menopause } \\
\qquad(\mathrm{n}=26)\end{array}$ & $\mathbf{p}$ \\
\hline Age, years & $60(54,65)$ & $48(45,60)$ & $<0.001$ \\
\hline Hot flashes & $52.8 \%$ & $92.3 \%$ & 0.001 \\
\hline Estradiol, pmol/L & $74(68,85)$ & $68(57,74)$ & $<0.001$ \\
\hline $\mathrm{FSH}, \mathrm{IU} / \mathrm{L}$ & $78(70,83)$ & $87(83,88)$ & $<0.001$ \\
\hline Testosterone, nmol/L & $1.3(1.1,1.6)$ & $1.1(0.9,1.2)$ & 0.024 \\
\hline DHEAS, nmol/L & $5.5(4.4,5.8)$ & $5.9(5.8,6.1)$ & $<0.001$ \\
\hline Menopause time, years & $9(3,16)$ & $11(4,19)$ & 0.787 \\
\hline HRT & $4.4 \%$ & $7.7 \%$ & 0.789 \\
\hline Height, m & $1.63(1.60,1.65)$ & $1.64(1.58,1.65)$ & 0.128 \\
\hline Waist, kg & $73(66,84)$ & $67(64,86)$ & 0.191 \\
\hline BMI, $\mathrm{kg} / \mathrm{m}^{2}$ & $27.3(25.7,31.6)$ & $25.8(24.2,32.0)$ & 0.233 \\
\hline SBP, mmHg & $140(120,150)$ & $120(115,160)$ & 0.054 \\
\hline DBP, mmHg & $90(80,100)$ & $80(75,100)$ & 0.526 \\
\hline CHD, angina pectoris & $30.6 \%$ & $26.9 \%$ & 0.765 \\
\hline Prior myocardial infarction & $3.2 \%$ & 0 & 0.799 \\
\hline Arterial hypertension & $56.2 \%$ & $53.8 \%$ & 0.847 \\
\hline Prior stroke & $2.5 \%$ & 0 & 0.841 \\
\hline Diabetes mellitus & $6.9 \%$ & $19.2 \%$ & 0.316 \\
\hline Smoking & $3.8 \%$ & $23.1 \%$ & 0.115 \\
\hline HR, beats/min & $72.6(65.2,80.1)$ & $71.8(66.0,75.8)$ & 0.567 \\
\hline SDNN, ms & $33.7(24.9,61.2)$ & $35.0(24.3,44.0)$ & 0.533 \\
\hline $\mathrm{CV}, \%$ & $4.3(2.9,6.9)$ & $3.9(3.0,6.2)$ & 0.486 \\
\hline RMSSD, ms & $27.3(16.3,59.5)$ & $27.3(16.5,44.3)$ & 0.548 \\
\hline PNN50 & $2.3(0.4,9.5)$ & $2.1(0.5,9.5)$ & 0.766 \\
\hline $\mathrm{HF}, \mathrm{ms}^{2}$ & $102.1(34.0,665.4)$ & $69.1(33.1,204.2)$ & 0.317 \\
\hline $\mathrm{LF}, \mathrm{ms}^{2}$ & $127.8(60.8,456.8)$ & $105.1(56.3,285.2)$ & 0.528 \\
\hline $\mathrm{HF}, \%$ & $26.8(14.7,41.0)$ & $23.9(13.7,38.3)$ & 0.483 \\
\hline LF, \% & $28.0(18.2,40.9)$ & $27.8(18.7,43.2)$ & 0.781 \\
\hline $\mathrm{S}, \%$ & $45.2(33.3,55.7)$ & $37.5(34.7,46.8)$ & 0.084 \\
\hline \multicolumn{4}{|c|}{$\begin{array}{l}\text { Continuous variables are presented as medians with inter-quartile ranges, Me (Q1, Q3). Categorical data are presented as percentages. FSH: } \\
\text { follicle stimulating hormone; DHEAS: dehydroepiandrosterone sulfate; HRT: hormone replacement therapy; BMI: body mass index; SBP: } \\
\text { systolic blood pressure; DBP: diastolic blood pressure; CHD: coronary heart disease; HR: heart rate; SDNN: standard deviation of the NN in- } \\
\text { terval (the time elapsing between two consecutive R waves in the electrocardiogram with normal sinus rhythm); CV: coefficient of variation; } \\
\text { RMSSD: square root of the mean squared differences of successive NN intervals; PNN50: proportion derived by dividing NN50: the number of } \\
\text { interval differences of successive NN intervals greater than } 50 \mathrm{~ms} \text {, by the total number of NN intervals; HF: high frequency band in absolute } \\
\text { values }\left(\mathrm{ms}^{2}\right) \text {; LF: low frequency band in absolute values }\left(\mathrm{ms}^{2}\right) \text {; HF\%: high frequency band in percentage of total spectral power; LF\%: low } \\
\text { frequency band in percentage of total spectral power; S: Index S of synchronization between the 0.1-Hz rhythms }\end{array}$} \\
\hline
\end{tabular}

time and $S$ index (Spearman $\mathrm{r}=-0.41, \mathrm{p}=0.039$ ). The absence of a statistically significant correlation with other autonomic indices may probably be explained by the small number of patients in this subgroup.

Multiple regression analysis did not reveal a significant relationship between cardiovascular autonomic indices and menopause time. We did not find a relationship between autonomic indices and BMI in pre- and postmenopausal women, including CVD patients $(p>0.05)$.

\section{Sex hormones and cardiovascular autonomic indices}

In our study, the correlation between cardiovascular autonomic indices and some sex hormones (FSH and testosterone) was similar to the correlation observed between the autonomic indices and menopause time. The data from all patients, including CVD patients, were analyzed.

Some cardiovascular autonomic indices showed a low correlation (Spearman $r<0.18, p<0.05$ ) with a number of sex hormones in the whole group $(n=289)$ : 
Table 3. Summary statistics for all variables in the discriminant models for classification of women into two groups (with hot flashes and without hot flashes) based on sex hormones

\begin{tabular}{|c|c|c|c|c|c|c|}
\hline No. & Variables & Wilks' Lambda & Partial Lambda & F-remove & p-level & Tolerance \\
\hline \multicolumn{7}{|c|}{ Premenopausal women } \\
\hline 1 & $\mathrm{FSH}^{*}$ & 0.76 & 0.95 & 4.80 & 0.031 & 0.15 \\
\hline 2 & Estradiol & 0.75 & 0.97 & 3.37 & 0.069 & 0.16 \\
\hline 3 & Age & 0.74 & 0.97 & 2.11 & 0.150 & 0.37 \\
\hline 4 & DHEAS & 0.73 & 0.98 & 1.44 & 0.233 & 0.31 \\
\hline 5 & CVD & 0.73 & 0.98 & 1.31 & 0.256 & 0.80 \\
\hline 6 & Testosterone & 0.72 & 0.99 & 0.47 & 0.496 & 0.12 \\
\hline 7 & BMI & 0.72 & 0.99 & 0.44 & 0.508 & 0.82 \\
\hline 8 & HRT & 0.72 & 0.99 & 0.17 & 0.684 & 0.85 \\
\hline \multicolumn{7}{|c|}{ Postmenopausal women } \\
\hline 1 & Estradiol* & 0.79 & 0.69 & 78.08 & $<0.001$ & 0.87 \\
\hline 2 & Age* & 0.56 & 0.97 & 4.66 & 0.032 & 0.58 \\
\hline 3 & Testosterone & 0.56 & 0.98 & 3.17 & 0.076 & 0.11 \\
\hline 4 & FSH & 0.56 & 0.98 & 2.85 & 0.093 & 0.16 \\
\hline 5 & BMI & 0.55 & 0.99 & 0.88 & 0.347 & 0.87 \\
\hline 6 & DHEAS & 0.55 & 0.99 & 0.79 & 0.373 & 0.19 \\
\hline 7 & HRT & 0.55 & 0.99 & 0.49 & 0.480 & 0.93 \\
\hline 8 & CVD & 0.55 & 0.99 & 0.18 & 0.672 & 0.87 \\
\hline
\end{tabular}

Table 4. Correlation of menopause time with sex hormone levels and cardiovascular autonomic indices

\begin{tabular}{|c|c|c|c|c|}
\hline \multirow[t]{2}{*}{ Parameters } & \multicolumn{2}{|c|}{ Natural menopause $(n=161)$} & \multicolumn{2}{|c|}{ Surgical menopause $(n=26)$} \\
\hline & Spearman $\mathbf{r}$ & $\mathbf{p}$ & Spearman $\mathbf{r}$ & $\mathbf{p}$ \\
\hline HR, beats/min & -0.03 & 0.717 & -0.20 & 0.347 \\
\hline SDNN, ms & 0.21 & 0.007 & 0.15 & 0.464 \\
\hline $\mathrm{CV}$ & 0,22 & 0.005 & 0.11 & 0.609 \\
\hline RMSSD, ms & 0.23 & 0.004 & 0.20 & 0.336 \\
\hline PNN50 & 0.24 & 0.002 & 0.06 & 0.791 \\
\hline $\mathrm{HF}, \mathrm{ms}^{2}$ & 0.22 & 0.005 & -0.01 & 0.978 \\
\hline $\mathrm{LF}, \mathrm{ms}^{2}$ & 0.17 & 0.030 & 0.06 & 0.790 \\
\hline $\mathrm{HF}, \%$ & 0.18 & 0.022 & -0.07 & 0.752 \\
\hline $\mathrm{LF}, \%$ & -0.06 & 0.473 & -0.09 & 0.671 \\
\hline $\mathrm{S}, \%$ & -0.08 & 0.317 & -0.41 & 0.039 \\
\hline
\end{tabular}

i) HR and $S$ index correlated with all sex hormones (estradiol ${ }^{\mathrm{P}}$, $\mathrm{FSH}^{\mathrm{n}}$, testosterone ${ }^{\mathrm{p}}$, and DHEAS ${ }^{\mathrm{n}}$ ), where superscripts $\mathrm{p}$ and $\mathrm{n}$ denote a positive and negative correlation, respectively ii) RMSSD, PNN50, HF, and HF\% correlated with FSH ${ }^{p}$, testosterone $^{\mathrm{n}}$, and DHEAS ${ }^{\mathrm{p}}$ iii) SDNN, CV, LF, and LF\% showed no correlation with any sex hormones

In premenopausal women, only testosterone exhibited a weak correlation with SDNN, CV, PNN50, RMSSD, HF, and HF\% (Spearman $\mathrm{R}$ ranged from 0.16 to $0.20, \mathrm{p}<0.05$ ). In postmenopausal women, the correlations were not found. 
After the exclusion of CVD patients, the correlation analysis gave the following results. In women without CVD, $\mathrm{S}$ index still correlated with all sex hormones (Spearman $\mathrm{R}$ ranged from 0.20 to $0.25, \mathrm{p}<0.05)$, while HF correlated only with $\mathrm{FSH}$ and DHEAS $(r=0.18, p=0.039$ and $r=0.21, p=0.016$, respectively). Other indices showed no correlation with sex hormones. Age had no effect on the relationship between cardiovascular autonomic indices and sex hormones in the women.

\section{Hot flashes and cardiovascular autonomic indices}

We studied the relationships between hot flashes (binary parameter yes/no) and several cardiovascular autonomic indices in pre- and postmenopausal women using discriminant models. The following indices were included in the models: HR, SDNN, LF\%, HF\%, and $S$ index. We also included age and the main predictors in the analysis. Patients with CVD were excluded from consideration to remove the uncontrolled effects of CVD on autonomic control.

We did not find any significant relationships between autonomic indices and the presence or absence of hot flashes. In premenopausal women, the constructed discriminant model (Wilks' lambda $=0.78$ and approximate $\mathrm{F}(7.62)=2.56$, $\mathrm{p}=0.022$ ) showed lower predictive power than the model presented in Table 3 . The percent of correctly classified cases using this model was $36.4 \%$ for women with hot flashes and $88.1 \%$ for women without hot flashes. The main predictor of hot flashes was also FSH.

In postmenopausal women, the constructed discriminant model had Wilks' lambda $=0.62$ and approximate $\mathrm{F}(7.47)=4.19$, $\mathrm{p}=0.001$. This model was also worse than the model presented in Table 3. In particular, the percent of correctly classified cases using this model was $68.8 \%$ and $73.9 \%$ for women with hot flashes and without them, respectively. The main predictor of hot flashes was estradiol.

\section{Discussion}

In our study, we found a significant difference in sex hormones between women with surgical and natural menopause. The obtained results are consistent with results reported by other authors $(30,31)$. Note that all women with surgical menopause included in our study were younger than 60 years. It is known that DHEAS level decreases with age (30). It is also known that smoking has an influence on steroid hormone concentrations (32). However, we did not find such an influence in our study. The impact of sex hormones on CVD in women is discussable and attracts a lot of attention (33-36). According to our study, sex hormones and menopause time are related similarly with some autonomic indices. According to Chaudhuri et al. (37), postmenopausal women exhibit significantly decreased HRV in comparison with premenopausal women. Some other differences between these groups of women were reported in other studies (38). We did not find significant relationships between the characteristics of menopausal status and autonomic indices, which are also considered cardiovascular risk factors $(2,3)$. Low correlations are discussable and have no clinical importance. In our study, only HR was different in pre- and postmenopausal women, including patients with CVD. This observation contradicts the increase of sympathetic tone after menopause (10), which results in the increase of HR. In women without CVD, some spectral HRV indices (LF and HF) were also different. However, CVD masks the relationship between autonomic control and menopause.

Note that arterial hypertension was more frequent in postmenopausal women in our study, which is consistent with other studies (39-40). In the postmenopausal period, the increase of $\mathrm{BP}$ is associated with autonomic disturbances in the CVS, in particular, with the increase of sympathetic tone (9). Diabetes mellitus was observed only in postmenopausal women. Other authors also reported a greater frequency of glucose metabolism disturbances after menopause (41).

Moodithaya et al. (42) have shown a decrease of power of $\mathrm{HF}$ and LF spectral bands in the HRV power spectrum in postmenopausal women in comparison with premenopausal women. Age was the important factor responsible for the differences in all ranges of the HRV spectrum between pre- and postmenopausal women.

Tezini et al. (43) suggested the absence of a relationship between autonomic control and ovarian hormone deprivation in rats with early and physiological menopause. These results seem to be a consequence of the aging process. We confirmed this fact in postmenopausal women. The low correlation between testosterone and some autonomic indices, shown by us in premenopausal women, is a debatable point. In postmenopausal women without prior HRT, oral estradiol therapy versus transdermal estradiol reduced HRV in the time domain (SDNN, RMSSD, and triangular index) (44). Hautamäki et al. (45) reported positive effects of estradiol-only therapy on cardiovascular control in flushing women. It was also shown that estrogen therapy has a weak attenuating effect on some nocturnal nonlinear measures of HRV (46). But, Fernandes et al. (47) did not find any effects of HRT on 24-hour HRV in postmenopausal women.

The difference in estrogen level between pre- and postmenopausal women contributed to the difference in relative values of HF and LF bands in the HRV spectrum (42). In our study, the power of HF and LF spectral bands of HRV was not significantly different in postmenopausal versus premenopausal women. However, in the analysis restricted to women without CVD, the index RMSSD and both the HF and LF bands were significantly higher in postmenopausal versus premenopausal women. The inclusion of women with CVD into the analysis led to the masking of the relationship between menopausal status and HF and LF. The results of our study may be limited by its cross-sectional design (see the Limitations section).

According to the results of cross-sectional study by CarranzaLira et al. (48), vasomotor symptoms (hot flashes and sweats) correlate only after menopause. Da Fonseca et al. (49) reported that the age of menopause and BMI may influence the intensity of vasomotor symptoms. In our cross-sectional study, the main predictors of hot flashes were sex hormone levels (FSH and estradiol in pre- and postmenopausal women, respectively). Autonomic indices and BMI were not related with hot flashes in 
the women studied. Lantto et al. (44) obtained similar results. They showed for postmenopausal women without HRT that HRV parameters are similar in subjects with hot flashes and without them. According to Hautamäki et al. (50), hot flashes and HRT were not related to the changes in HRV.

The absence of clinically meaningful relationships between cardiovascular autonomic indices and vasomotor symptoms in menopause revealed in our study agree with some other results $(5,10,11,44,50)$. It is evident that changes in levels of sex hormones in menopause are the main factor determining vasomotor symptoms. The observed relationships between a number of autonomic indices and the level of sex hormones and menopause time indirectly indicate that autonomic indices exert an influence on the appearance of menopause symptoms. Interrelations between autonomic indices and vasomotor symptoms in menopause need further investigation.

Also, we did not find any relationship between autonomic indices and BMI, which is consistent with Moodithaya et al. (42). However, Mouridsen et al. (51) reported that weight loss seems to improve HRV. A relationship between BMI and LF and HF band of the HRV spectrum was reported only in premenopausal women $(18,52)$. The decrease of HF and increase of LF may be associated with central adiposity in postmenopausal women (53). According to Robillard et al. (54), healthy women with a metabolically healthy but obese (MHO) phenotype had significantly lower resting HR and higher SDNN and LF than women with obesity as a risk factor.

In our cross-sectional study, we did not reveal a clinically important relationship between cardiovascular autonomic control and menopausal status (pre- and postmenopausal period, menopausal time, sex hormones, and hot flashes) in women. A significant difference between pre- and postmenopausal women was found in a number of autonomic indices (HR, LF, and HF). In the case of CVD, there was no difference in LF and HF between the subgroups of women studied. The observed weak correlations between autonomic indices and some other parameters (hot flashes, sex hormones, menopausal time, and obesity) have no clinical impact. FSH was found to be the main predictor of hot flashes in premenopausal women in our study, while estradiol and age were found to be the main predictors of hot flashes in postmenopausal women.

Personal dynamics of sex hormone levels during menopause were not studied. The cross-sectional design of the presented study had some limitations. We can not examine individual dynamic features of the relationship between cardiovascular autonomic control and fertile status (sex hormone levels, menopause time, etc.). An additional comparative study of cardiovascular autonomic control features in pre- and postmenopausal women must be carried out during a prospective trial.

The overlap in age between pre- and post-menopausal women was small, because it was difficult to adjust for age accurately. Therefore, it was difficult to determine the influence of age on menopausal status. The small number of women with surgical menopause was a limitation of our study for the corresponding subgroup.

We did not study the duration of sleep among women. Since patients with menopause often have sleep disturbances, which can affect HRV indices, it is also a limitation of the present study. We did not assess lipids and diet in women. An influence of lipid metabolism and diet type on CVS autonomic control was shown in some studies (55). We did not identify women with the MHO phenotype among obesity subjects. The influence of BMI on autonomic indices needs further investigation.

Ethics Committee Approval: Ethics committee approval was received for this study from the ethics committee of Saratov Research Institute of Cardiology (no. 24, 12 Sept 2013).

Informed Consent: Written informed consent was obtained from patients who participated in this study.

Peer-review: Externally peer-reviewed.

Author contributions: Concept - I.W.N., A.R.K.; Design - I.W.N., A.R.K., M.D.P.; Supervision - V.I.G., V.I.P., B.P.B.; Resource - B.P.B., I.W.N.; Materials - I.W.N., A.S.K.; Data Collection\&/or Processing - I.W.N., V.I.G.; Analysis\&/or Interpretation - A.R.K., A.S.K., M.D.P.; Literature Search I.W.N., A.R.K., A.S.K.; Writing - A.R.K., M.D.P.; Critical Reviews - M.D.P., V.I.G., V.I.P., B.P.B.

Conflict of Interest: No conflict of interest was declared by the authors.

Financial Disclosure: This work was supported by the President of the Russian Federation, Grant No. MK-2267.2014.8, and the Russian Foundation for Basic Research, Grant No. 14-08-31145.

\section{References}

1. Kannel WB, Hjortland MC, McNamara PM, Gordon T. Menopause and risk of cardiovascular disease: the Framingham study. Ann Intern Med 1976; 85: 447-52. [CrossRef]

2. Heart rate variability: Standards of measurement, physiological interpretation, and clinical use. Task Force of the European Society of Cardiology and the North American Society of Pacing and Electrophysiology. Circulation. 1996; 93: 1043-65. [CrossRef]

3. Kiselev AR, Gridnev VI, Prokhorov MD, Karavaev AS, Posnenkova OM, Ponomarenko VI, et al. Evaluation of 5-Year Risk of Cardiovascular Events in Patients after Acute Myocardial Infarction Using Synchronization of $0.1-\mathrm{Hz}$ Rhythms in Cardiovascular System. Ann Noninvasive Electrocardiol 2012; 17: 204-13. [CrossRef]

4. Kuo TB, Lin T, Yang CC, Li CL, Chen CF, Chou P. Effect of aging on gender differences in neural control of heart rate. Am J Physiol 1999; 277: H2233-9

5. Ribeiro TF, Azevedo GD, Crescencio JC, Maraes VR, Papa V, Catai $\mathrm{AM}$, et al. Heart rate variability under resting conditions in postmenopausal and young women. Braz J Med Biol Res 2001; 34: 871-7. [CrossRef]

6. Acharya UR, Kannathal N, Sing OW, Ping LY, Chua T. Heart rate analysis in normal subjects of various age groups. Biomed Eng Online 2004; 3: 24. [CrossRef]

7. Brockbank CL, Chatterjee F, Bruce SA, Woledge RC. Heart rate and its variability change after the menopause. Exp Physiol 2000; 85: 327-30.

8. Liu CC, Kuo TB, Yang CC. Effects of estrogen on gender-related autonomic differences in humans. Am J Physiol Heart Circ Physiol 2003; 285: H2188-93. [CrossRef]

9. Vongpatanasin W. Autonomic regulation of blood pressure in menopause. Semin Reprod Med 2009; 27: 338-45. [CrossRef]

10. Lee JO, Kang SG, Kim SH, Park SJ, Song SW. The relationship between menopausal symptoms and heart rate variability in middle aged women. Korean J Fam Med 2011; 32: 299-305. [CrossRef] 
11. Thurston RC, Christie IC, Matthews KA. Hot flashes and cardiac vagal control: a link to cardiovascular risk? Menopause 2010; 17: 456-61.

12. Virtanen I, Polo O, Polo-Kantola P, Kuusela T, Ekholm E. The effect of estrogen replacement therapy on cardiac autonomic regulation. Maturitas 2000; 37: 45-51. [CrossRef]

13. Christ M, Seyffart K, Tillmann HC, Wehling M. Hormone replacement in postmenopausal women: impact of progestogens on autonomic tone and blood pressure regulation. Menopause 2002; 9: 127-36. [CrossRef]

14. Farag NH, Nelesen RA, Parry BL, Loredo JS, Dimsdale JE, Mills PJ. Autonomic and cardiovascular function in postmenopausal women: the effects of estrogen versus combination therapy. Am J Obstet Gynecol 2002; 186: 954-61. [CrossRef]

15. Rosa Brito-Zurita O, Posadas-Romero C, Hermosillo AG, ZamoraGonzalez J, Hernandez-Ono A, Cardoso-Saldana G, Torres-Tamayo M. Estrogen effect on heart rate variability in hypertensive postmenopausal women. Maturitas 2003; 44: 39-48. [CrossRef]

16. Virtanen I, Polo O, Saaresranta T, Kuusela T, Polo-Kantola P, Ekholm E. Medroxyprogesterone improves cardiac autonomic control in postmenopausal women with respiratory insufficiency. Respir Med 2004; 98: 126-33. [CrossRef]

17. Neves VF, Silva de Sá MF, Gallo L Jr, Catai AM, Martins LE, Crescêncio JC, et al. Autonomic modulation of heart rate of young and postmenopausal women undergoing estrogen therapy. Braz J Med Biol Res 2007; 40: 491-9. [CrossRef]

18. Monda M, Messina G, Vicidomini C, Viggiano A, Mangoni C, De Luca B. Activity of autonomic nervous system is related to body weight in pre-menopausal, but not in post-menopausal women. Nutr Neurosci 2006; 9: 141-5. [CrossRef]

19. Malpas SC. Neural influences on cardiovascular variability: Possibilities and pitfalls. Am J Physiol Heart Circ Physiol 2002; 282: 6-20.

20. Cohen MA, Taylor JA. Short-term cardiovascular oscillations in man: Measuring and modeling the physiologies. J Physiol 2002; 542: 669-83. [CrossRef]

21. Karavaev AS, Prokhorov MD, Ponomarenko VI, Kiselev AR, Gridnev VI, Ruban EI, Bezruchko BP. Synchronization of low-frequency oscillations in the human cardiovascular system. Chaos 2009; 19: 033112. [CrossRef]

22. Kiselev AR, Gridnev VI, Karavaev AS, Posnenkova OM, Prokhorov MD, Ponomaremko VI et al. The Dynamics of $0.1 \mathrm{~Hz}$ Oscillations Synchronization in Cardiovascular System during the Treatment of Acute Myocardial Infarction Patients. Applied Medical Informatics 2011; 28: 1-8.

23. Kiselev AR, Gridnev VI, Prokhorov MD, Karavaev AS, Posnenkova OM, Ponomarenko VI et al. Selection of optimal dose of beta-blocker treatment in myocardial infarction patients based on changes in synchronization between $0.1 \mathrm{~Hz}$ oscillations in heart rate and peripheral microcirculation. Journal of Cardiovascular Medicine 2012; 13: 491-8. [CrossRef]

24. Rhee S, Yang B-H, Asada $\mathrm{H}$. Theoretical evaluation of the influence of displacement on finger photoplethysmography for wearable health monitoring sensors. Symposium on Dynamics, Control, and Design of Biomechanical Systems ASME International Mechanical Engineering Congress and Exposition, Nashville, Tennessee, November 14-19, 1999.

25. Söderström T, Stefanovska A, Veber M, Svensson H. Involvement of sympathetic nerve activity in skin blood flow oscillations in humans. Am J Physiol Heart Circ Physiol 2003; 284: 1638-46. [CrossRef]

26. Bandrivskyy A, Bernjak A, McClintock PVE, Stefanovska A. Wavelet phase coherence analysis: application to skin temperature and blood flow. Cardiovasc Eng. 2004; 4: 89-93. [CrossRef]
27. Anschutz S, Schubert R. Modulation of the myogenic response by neurogenic influences in rat small arteries. Br J Pharmacol 2005; 146: 226-33. [CrossRef]

28. Bernjak A, Clarkson PBM, McClintock PVE, Stefanovska A. Lowfrequency blood flow oscillations in congestive heart failure and after $\beta 1$-blockade treatment. Microvasc Res 2008; 76: 224-32. [CrossRef]

29. Taylor R. Interpretation of the correlation coefficient: a basic review. JDMS 1990; 1: 35-39.

30. Barrett-Connor E, Goodman-Gruen D. The epidemiology of DHEAS and cardiovascular disease. Ann N Y Acad Sci 1995; 774: 259-70. [CrossRef]

31. Davison SL, Bell R, Donath S, Montalto JG, Davis SR. Androgen levels in adult females: changes with age, menopause, and oophorectomy. J Clin Endocrinol Metab 2005; 90: 3847-53. [CrossRef]

32. Soldin OP, Makambi KH, Soldin SJ, O'Mara DM. Steroid hormone levels associated with passive and active smoking. Steroids 2011; 76: 653-9. [CrossRef]

33. Pappa T, Alevizaki M. Endogenous sex steroids and cardio- and cerebro-vascular disease in the postmenopausal period. Eur $\mathrm{J}$ Endocrinol 2012; 167: 145-56.

34. Wang L, Szklo M, Folsom AR, Cook NR, Gapstur SM, Ouyang P. Endogenous sex hormones, blood pressure change, and risk of hypertension in postmenopausal women: the Multi-Ethnic Study of Atherosclerosis. Atherosclerosis 2012; 224: 228-34. [CrossRef]

35. El Khoudary SR, Wildman RP, Matthews K, Thurston RC, Bromberger JT, Sutton-Tyrrell K. Endogenous sex hormones impact the progression of subclinical atherosclerosis in women during the menopausal transition. Atherosclerosis 2012; 225: 180-6. [CrossRef]

36. Crandall CJ, Barrett-Connor E. Endogenous sex steroid levels and cardiovascular disease in relation to the menopause: a systematic review. Endocrinol Metab Clin North Am 2013; 42: 227-53. [CrossRef]

37. Chaudhuri A, Borade NG, Hazra SK. A study of heart rate variablity tests and lipid profile in postmenopausal women. J Indian Med Assoc 2012; 110: 228, 230-2.

38. Ryś A, Ryś A, Kogut P, Thor PJ. Menopausal changes in circadian heart rate variability. Folia Med Cracov. 2006; 47: 69-78.

39. Staessen J, Ginocchio G, Thijs L, Fagard R. Conventional and ambulatory blood pressure and menopause in a prospective population study. J Hum Hypertens 1997; 11: 507-14. [CrossRef]

40. Wassertheil-Smoller S, Anderson G, Psaty BM, Black HR, Manson $\mathrm{J}$, Wong $\mathrm{N}$, et al. Hypertension and its treatment in postmenopausal women: baseline data from Women's Health Initiative. Hypertension 2000; 36: 780-9. [CrossRef]

41. Martínez JA, Palacios S, Chavida F, Pérez M. Urban-rural differences in Spanish menopausal women. Rural Remote Health 2013; 13: 1865.

42. Moodithaya SS, Avadhany ST. Comparison of cardiac autonomic activity between pre and post menopausal women using heart rate variability. Indian J Physiol Pharmacol 2009; 53: 227-34.

43. Tezini GC, Becari C, Zanotto CZ, Salgado MC, Passaglia Rde C, Souza HC. Ageing is the main determinant of haemodynamics and autonomic cardiac changes observed in post-menopausal female rats. Auton Neurosci 2013; 174: 36-41. [CrossRef]

44. Lantto $\mathrm{H}$, Haapalahti $\mathrm{P}$, Tuomikoski $\mathrm{P}$, Viitasalo $\mathrm{M}$, Väänänen $\mathrm{H}$, Sovijärvi AR, et al. Vasomotor hot flashes and heart rate variability: a placebo-controlled trial of postmenopausal hormone therapy. Menopause 2012; 19: 82-8. [CrossRef]

45. Hautamäki H, Haapalahti $P$, Piirilä $P$, Tuomikoski $P$, Sovijärvi A, Ylikorkala O, Mikkola TS. Effect of hot flushes on cardiovascular autonomic responsiveness: a randomized controlled trial on hormone therapy. Maturitas 2012; 72: 243-8. [CrossRef] 
46. Virtanen I, Ekholm E, Polo-Kantola P, Hiekkanen H, Huikuri H. Postmenopausal estrogen therapy modulates nocturnal nonlinear heart rate dynamics. Menopause 2008; 15: 693-7. [CrossRef]

47. Fernandes EO, Moraes RS, Ferlin EL, Wender MC, Ribeiro JP. Hormone replacement therapy does not affect the 24-hour heart rate variability in postmenopausal women: results of a randomized, placebo-controlled trial with two regimens. Pacing Clin Electrophysiol 2005; 28 Suppl 1: S172-7. [CrossRef]

48. Carranza-Lira S, Sandoval-Hernández CI. Comparison of the frequency and magnitude of the vasomotor symptoms in premenopausal and postmenopausal women from Mexico City. Ginecol Obstet Mex 2013; 81: 127-32.

49. Da Fonseca AM, Bagnoli VR, Souza MA, Azevedo RS, Couto Ede B Jr, Soares JM Jr, Baracat EC. Impact of age and body mass on the intensity of menopausal symptoms in 5968 Brazilian women. Gynecol Endocrinol 2013; 29: 116-8. [CrossRef]

50. Hautamäki H, Mikkola TS, Sovijärvi AR, Piirilä P, Haapalahti P. Menopausal hot flushes do not associate with changes in heart rate variability in controlled testing: a randomized trial on hormone therapy. Acta Obstet Gynecol Scand 2013; 92: 902-8. [CrossRef]
51. Mouridsen MR, Bendsen NT, Astrup A, Haugaard SB, Binici Z, Sajadieh A. Modest weight loss in moderately overweight postmenopausal women improves heart rate variability. Eur J Prev Cardiol 2013; 20: 671-7. [CrossRef]

52. Vallejo M, Márquez MF, Borja-Aburto VH, Cárdenas M, Hermosillo AG. Age, body mass index, and menstrual cycle influence young women's heart rate variability - a multivariable analysis. Clin Auton Res 2005; 15: 292-8. [CrossRef]

53. Franz R, Maturana MA, Magalhães JA, Moraes RS, Spritzer PM. Central adiposity and decreased heart rate variability in postmenopause: a cross-sectional study. Climacteric 2013; 16: 576-83. [CrossRef]

54. Robillard MÈ, Bellefeuille P, Comtois AS, Aubertin-Leheudre M, Karelis AD. The metabolically healthy but obese postmenopausal woman presents a favourable heart rate variability profile. Scand Cardiovasc J 2011; 45: 316-20. [CrossRef]

55. Fu CH, Yang CC, Lin CL, Kuo TB. Alteration of cardiovascular autonomic functions by vegetarian diets in postmenopausal women is related to LDL cholesterol levels. Chin J Physiol 2008; 51: 100-5. 